3

4

\title{
The Military Academic Motivation Scale (MAMS)
}

\section{A New Scale to Assess Motivation Among Military Cadets From a Self-Determination Theory Perspective}

\author{
Lorenzo Filosa ${ }^{1} \odot$, Gianluca Cepale ${ }^{1}$, Enrico Perinelli ${ }^{2}$, Luigi Cinque ${ }^{3,4}$, \\ Alessandra Coscarelli ${ }^{4}$, and Guido Alessandri ${ }^{1}$
}

\author{
[Author: add department]Faculty of Medicine and Psychology, Sapienza, University of Rome, Italy \\ ${ }^{2}$ [Author: add department] University of Trento, Italy \\ ${ }^{3}$ [Author: add department]General Headquarters of Guardia di Finanza, Italy \\ ${ }^{4}$ [Author: add department] Inspectorate for Training Institutes of Guardia di Finanza, Italy
}

\begin{abstract}
The purpose of the present paper is to introduce the Military Academic Motivation Scale (MAMS), a short and reliable instrument for assessing the different types of motivation among military cadets. Three representative samples of military cadets completed the MAMS. In Study $1(N=452)$, the hypothesized five-factor structure of the MAMS was empirically tested and supported. In Study $2(N=1,372)$, the factorial invariance across both gender and cohorts of the MAMS was explored and confirmed. Study $3(N=520)$ provided evidence of the external validity of the five MAMS factors with respect to important organizational outcomes (work engagement, organizational commitment, job performance, extra-role behaviors, burnout, and intention to quit). The potential applications of the MAMS were extensively discussed, and recommendations for use in the military Academy setting were given.
\end{abstract}

Keywords: motivation, self-determination theory, exploratory structural equation modeling, measurement invariance, military academy

Motivation plays a key role in the military academy. Military organizations are indeed "greedy institutions" demanding of cadets a continuous investment of physical and psychological resources (see Segal, 1986). Once entered in the academy, cadets are called to undergo a tiring and often harsh military training (Caforio, 2018), to conform to strict conduct rules (Soeters, 2018), to respect a highly formalized hierarchical role system (Soeters, 2018), and to accept a certain lack of separation between private and working life (Hall, 2011). Thus, it is not surprising that several psychological studies have demonstrated a strict association between levels of reported motivation and workplace well-being (Chambel, Castanheira, OliveiraCruz, \& Lopes, 2015), work engagement (Gillet, Huart, Colombat, \& Fouquereau, 2013), physical symptoms and future work intentions (Otis \& Pelletier, 2005), perceived occupational injury (Chan et al., 2017), and career retention in military settings (Gibb \& Dolgin, 1988).

One of the most influential and useful theoretical accounts of human motivation has been offered by the self-determination theory (henceforth SDT; Deci \& Ryan, 1985; Ryan \& Deci, 2017). Notably, SDT does not describe motivation as a unitary construct. Rather, SDT postulates the existence of different types of motivation that jointly concur to determine people's behavior. Moreover, according to Ryan and Deci (2017, p. 14), "some forms of motivation are considered to be entirely volitional, reflecting one's interests or values, whereas others can be wholly external, as when one is coerced or pressured into doing something he or she does not find of value." Only internally motivated people are expected to engage and succeed in a task. Thus, being able to reliably discern and assess the different motivational inclinations characterizing cadets is important to evaluate the strength of their intention to undertake a career in the military.

For sure, there are high personal and organizational costs associated with failure to complete the military training (Dahlman, 2007). People who drop out of the academy suffer the costs of the time lost, of the personal resources depleted, and of all sacrifices made without obtaining the desired aim. On the other side, military organizations pay the cost of the economic resources invested and lost to train people who, at the end, quit their organization. Although less apparent at first, there are also other (often high) costs associated with ignoring the nature of motivation of people attending military academies and schools, and being finally 
admitted to exert an active role in the military. As noted by Caforio and Nuciari (1994), it is likely that internally motivated people would invest more and have no reserve in their work, and will generally show higher dedication and commitment. On the contrary, externally motivated people may, in the long run, show a more practical orientation and do things only when a personal advantage is clear (but see Kanfer, Frese, \& Johnson, 2017, p. 340; see also Cerasoli, Nicklin, \& Ford, 2014).

In this regard, several authors have explained the existence of two military cultures, one more occupationally (or bureaucratically) oriented, and the other more professionally oriented (Caforio, 2018). The adherence of a person to one or the other of these two cultures is likely explainable by the nature of his/her motivation to be part of military organizations. People belonging to the first culture likely choose to enter the military academy because of external motivations, such as the desire for economic independence, or a personal interest in getting a good education, or to gain job security (also in relation to unemployment situations), or simply a decent salary (see Caforio, 2018). People belonging to the second culture, on the other hand, appear to be more intrinsically motivated to choose military organizations. When questioned about it, they mention reasons such as "I wanted to play my part in serving my country," or "I was interested in leading men," or even "I was looking for adventure, because of military ethics" (Caforio, 2018, p. 282). Thus, knowing the nature of a cadet's motivations is a key aspect in order to predict his/her future engagement and commitment to the service.

Thus, the purpose of the present article is to report three studies aimed at investigating the psychometric properties of a new instrument developed to assess motivation to join the military. The remaining sections are organized as follows. First, we present the basic tenets of the SDT. Then, we present the development of this new scale. Finally, we describe the three studies conducted to investigate the psychometric properties of this new instrument, in terms of structural validity, reliability, measurement invariance, and external validity.

\section{Self-Determination Theory of Motivation}

From a theoretical stance, SDT treats motivation as a multidimensional construct and differentiates between forms of autonomous motivation and controlled motivation. The first is characterized by a strong volition and willingness to engage in certain behaviors (Deci \& Ryan, 2008). The latter leads people to act in response to external pressures or to attain certain rewards (Deci \& Ryan, 2008). Then, three further types of motivations, along with six associated behavior regulation styles, are distinguished and posited on a continuum from the maximum degree of controlled motivation (viz. non-self-determined) to the maximum degree of autonomous motivation (viz. self-determined; Gagné \& Deci, 2005; Ryan \& Deci, 2000). When motivation is autonomous and voluntary, the source of the behavior is hypothesized to be internal. In these circumstances, the behavior is considered to be self-determined. In contrast, when motivation is controlled by outer forces, beyond one's own real volition or control, the source of the behavior is deemed external. Consequently, the behavior is hypothesized to be not self-determined (Ryan \& Deci, 2017).

Amotivation is the most controlled or non-self-determined form of motivation. It is defined as a state characterized by a total absence of volition, and by the lack of any motivation to engage in behaviors perceived beyond one's control (Vallerand et al., 1992). Extrinsic motivation is less controlled than amotivation but lies on the non-selfdetermined side of the continuum (Ryan \& Deci, 2000). Within extrinsic motivation, four behavior regulation styles are acknowledged: external regulation and introjected regulation (i.e., the most controlled and involuntary forms), identified regulation and integrated regulation (i.e., the most autonomous and voluntary forms). Externally regulated individuals engage in a certain behavior in order to satisfy external demands, obtaining rewards or avoiding punishments; basically, work-related behaviors of externally regulated workers are "instrumental." Introjected regulation refers to controlled motivation that leads individuals to behave in order to avoid anxiety, guilt, or sense of remorse and to satisfy internal demands such as ego and self-esteem enhancement. Identified regulation refers to autonomous motivation for which the behavior is considered to be more conscious and personally important because it is more congruent with personal goals and values. Finally, integrated regulation refers to the most autonomous form of extrinsic motivation, which represents the perfect synthesis of one's interests and needs together with the values of another person or of society (Ryan \& Deci, 2000).

Intrinsic motivation lies at the opposite side of the selfdetermination continuum, representing the most autonomous and completely self-determined form of motivation. Internally motivated individuals act only because of the pure satisfaction derived by doing the activity itself. Thus, intrinsically motivated people are considered to be entirely self-determined and autonomous, with the origin of their intention being completely internal and determined by the profound pleasure derived from the activity itself. People intrinsically motivated, feel completely competent and in control, and they enjoy what they are doing referring feelings to be deeply interested and satisfied. The progression among those types of motivation is subordinate to fulfilling the basic needs for autonomy, competence, and relatedness (Deci \& Ryan, 2008; Ryan \& Deci, 2000). 


\section{Development of the Military Academic Motivation Scale}

Probably, the most acknowledged instrument developed for assessing motivation according to SDT is the Academic Motivation Scale (AMS; Vallerand et al., 1992). Since its introduction, the AMS was validated in different samples of high school and college students across different cultures (e.g., English and French; Vallerand et al., 1992, 1993). The original version of the AMS was composed of seven subscales, one assessing amotivation, three assessing different subtypes of external motivation (i.e., external regulation, introjected regulation, identified regulation), and the remaining three assessing different types of intrinsic motivation (i.e., intrinsic motivation to know, to accomplish things, and to experience stimulus; Vallerand, Blais, Brière, \& Pelletier, 1989; Vallerand et al., 1992, 1993). These last three types of intrinsic motivation were not theorized by SDT, nor have they been found anymore in subsequent psychometric studies on the instrument. In fact, more recent studies that have analyzed the factorial structure of the AMS have recovered only one dimension for intrinsic motivation (and thus, a total of only five subscales; see Grouzet, Otis, \& Pelletier, 2006; Otis, Grouzet, \& Pelletier, 2005; Ratelle, Guay, Larose, \& Senécal, 2004). Moreover, previous studies showed a high degree of overlap with integrated motivation subscale and problems of face validity (Gagné et al., 2015), leading Gagné and colleagues to argue that "adding an integrated regulation subscale [...] would lengthen the measure with no apparent benefits" (Gagné et al., 2015, p. 193).

Summarizing, to date there is compelling evidence that the AMS is composed by the following five subscales: (1) amotivation, (2) three subscales for extrinsic motivation (external regulation, introjected regulation, identified regulation), and (3) one subscale assessing intrinsic motivation. Each of these subscales consists of four items (Grouzet et al., 2006). Thus, in this paper we present a modified version of the above five factor AMS adapted for use in military academies and schools. This scale was named the Military Academic Motivation Scale (henceforth MAMS). Differently from other instruments suited for assessing motivation in the work setting (e.g., the Multidimensional Work Motivation Scale; see Gagné et al., 2015), the 20 items included in the MAMS were drawn from the original AMS (Vallerand et al., 1992, 1993), and specifically adapted for the military context.

More in detail, whereas the items included in the MAMS remained similar in meaning to the items originally included in the AMS, they were specifically rewritten and reframed for the military academic context thanks to the help of trained military psychologists, so that their content was framed explicitly on the military academy experience. Then, before being included in the final version of the MAMS, each of the original 20 items was judged by a pool of experts (two military psychologists enlisted as military officers and two researchers), blinded [Author: provide blinded details] to the aim of the present study, who were asked to assign each item to one of the five theoretical motivational dimensions tapped by the MAMS. During this process, three items (one for external regulation and two for intrinsic regulation) were discharged because their content was ambiguous and not easily suitable for the military context.

Thus, the final version of the MAMS used in this study was composed of 17 items (see Appendix): Four items for the amotivation subscale, three for the external regulation subscale, three for the introjected regulation subscale, three for the identified regulation subscale, and four for the intrinsic regulation subscale. These items are presented in Table 1. Structurally, the MAMS is composed of five factors, one for amotivation (consisting of 4 items); three for extrinsic motivation, namely external regulation (3 items), introjected regulation ( 3 items), identified regulation ( 3 items); and one for intrinsic motivation ( 4 items). Consistently with the original instrument, a 5-point Likert scale ranging from 1 (= not at all) to 5 (= very $m u c h$ ) was selected as the response format.

It is important to note that, whereas other instruments make specific reference to workers' "efforts" on an unspecified "current job" (see, e.g., Gagné et al., 2015), the items of the MAMS are focused on the motivations underlying the decision to undertake a military job. Hence, MAMS items are particularly suitable for assessing motivation before and across the training phases (i.e., at the academy), namely when cadets have not yet reached the status of tenured soldiers. Three studies are presented below in which the psychometric properties of the MAMS were evaluated in three different samples of military cadets.

\section{Study 1}

In Study 1, the hypothesized five-factor structure of the MAMS scale was investigated by means of exploratory structural equation modeling (ESEM), conducted on a large and heterogeneous sample of military officials, and noncommissioned officer cadets. Moreover, the reliability of factor scores belonging to each of the five factors was evaluated, as well as the item-scale corrected correlation.

\section{Method}

\section{Participants}

The participants of Study 1 were 452 military cadets attending both a military academy (28; $6 \%$ of the total), and a school for non-commissioned officers of the Guardia di Finanza $(424 ; 94 \%$ of the total), which is an Italian law 
Table 1. Means, standard deviations, item-total correlations of MAMS items and nonlinear SEM reliability coefficient of the subscales - Study 1, Study 2, and Study 3

\begin{tabular}{|c|c|c|c|c|c|c|c|c|c|}
\hline \multirow[b]{2}{*}{ Items } & \multicolumn{3}{|c|}{ Study $1(N=452)$} & \multicolumn{3}{|c|}{ Study $2(N=1372)$} & \multicolumn{3}{|c|}{ Study $3(N=520)$} \\
\hline & M & $S D$ & $r_{\mathrm{tt}}$ & $M$ & $S D$ & $r_{\mathrm{tt}}$ & $M$ & $S D$ & $r_{\mathrm{tt}}$ \\
\hline Amotivation $\left(\rho_{\mathrm{NL}}=.84, .87, .91\right)$ & 1.09 & 0.32 & & 1.08 & 0.35 & & 1.16 & 0.47 & \\
\hline Item 3 & 1.07 & 0.31 & .65 & 1.08 & 0.42 & .69 & 1.20 & 0.66 & .70 \\
\hline Item 7 & 1.10 & 0.42 & .66 & 1.10 & 0.46 & 69 & 1.17 & 0.55 & .77 \\
\hline Item 10 & 1.10 & 0.47 & .61 & 1.08 & 0.41 & .66 & 1.12 & 0.46 & .70 \\
\hline Item 15 & 1.08 & 0.39 & .65 & 1.07 & 0.40 & .73 & 1.13 & 0.53 & .79 \\
\hline External Regulation $\left(\rho_{\mathrm{NL}}=.81, .74, .87\right)$ & 2.12 & 0.92 & & 2.15 & 0.93 & & 2.05 & 0.84 & \\
\hline Item 5 & 2.05 & 1.07 & .59 & 2.08 & 1.08 & .56 & 2.06 & 0.97 & .60 \\
\hline Item 12 & 2.47 & 1.26 & .47 & 2.51 & 1.33 & .49 & 2.30 & 1.13 & .61 \\
\hline Item 17 & 1.83 & 1.03 & 69 & 1.85 & 1.03 & .70 & 1.79 & 0.89 & .72 \\
\hline Introjected Regulation $\left(\rho_{\mathrm{NL}}=.80, .80, .85\right)$ & 2.56 & 1.15 & & 2.58 & 1.16 & & 2.49 & 1.08 & \\
\hline Item 4 & 2.39 & 1.35 & .62 & 2.41 & 1.35 & .60 & 2.38 & 1.25 & .65 \\
\hline Item 11 & 2.48 & 1.33 & 69 & 2.53 & 1.36 & .69 & 2.45 & 1.26 & .72 \\
\hline Item 16 & 2.80 & 1.44 & .59 & 2.79 & 1.44 & .62 & 2.63 & 1.26 & .68 \\
\hline Identified Regulation $\left(\rho_{\mathrm{NL}}=.70, .75, .81\right)$ & 3.45 & 0.95 & & & 0.98 & & 3.24 & 0.93 & \\
\hline Item 6 & 3.84 & 1.21 & .43 & & 1.19 & .49 & 3.46 & 1.16 & .48 \\
\hline Item 8 & 3.47 & 1.21 & .36 & 3.55 & & .46 & 3.35 & 1.15 & .45 \\
\hline Item 9 & 3.03 & 1.35 & & 3.12 & 1.36 & .58 & 2.90 & 1.20 & .66 \\
\hline Intrinsic Regulation $\left(\rho_{\mathrm{NL}}=.86, .85, .89\right)$ & 4.55 & 0.58 & & 4.55 & & & 4.35 & 0.63 & \\
\hline Item 1 & 4.57 & 0.70 & & & 0.67 & 68 & 4.32 & 0.73 & .76 \\
\hline Item 2 & 4.66 & 0.63 & .77 & & 0.56 & .70 & 4.44 & 0.66 & .75 \\
\hline Item 13 & 4.46 & & .60 & & 0.80 & .57 & 4.38 & 0.76 & .73 \\
\hline Item 14 & 4.51 & & .63 & 4.46 & 0.82 & .62 & 4.25 & 0.82 & .67 \\
\hline
\end{tabular}

Note. The introduction to the scale reads "Why did you decide to join the Guardia di Finanza?". $\rho_{\mathrm{NL}}=$ Nonlinear SEM Reliability Coefficient for Study 1 , Study 2, and Study 3, respectively; $M=$ mean; $S D=$ standard deviation; $r_{\mathrm{tt}}=$ item-total scale-score-corrected correlation coefficient. Items are presented in Appendix.

enforcement agency of the Ministry of Economy and Finance. They were aged between 18 and 31 years $(M=$ 23.4, $S D=2.6)$. Sample consisted of 260 males $(57.5 \%)$ and 192 females $(42.5 \%)$. Most of the sample had a high school degree (316; 70\%), whereas 136 participants (30\%) had a university degree. Some of them also had previous experience in another military organization (167; 37\%). There were no missing data.

\section{Procedure}

Military cadets provided their responses after logging into computers in the school under the direct supervision of a specifically trained psychologist. The psychologist did not interfere in any way with participants, but only introduced them to the procedure and showed them how to interact with the electronic version of the test battery. All the cadets completed the Italian version of the tests during the same day, but in different groups randomly assembled. This study (as well as the other two) was conducted according to the ethical standards of the American Psychological Association (APA), and according to the principles expressed in the Declaration of Helsinki.

\section{Measure}

As presented above, the MAMS was composed of 17 items (see Appendix): Four items for the amotivation subscale, three for the external regulation subscale, three for the introjected regulation subscale, three for the identified regulation subscale, and four for the intrinsic regulation subscale. These items are presented in Table 1 . The response format is a 5 -point Likert scale ranging from 1 (= not at all to 5 (= very much).

\section{Data Analytic Strategy and Model Evaluation}

The hypothesized five-factor model was tested using Exploratory Structural Equation Models (henceforth, ESEM; Asparouhov \& Muthén [Author: add to references list], 2009; Marsh, Morin, Parker, \& Kaur, 2014). ESEM integrates features of confirmatory factor analysis (CFA) and exploratory factor analysis (EFA) allowing researchers to evaluate the fit of alternative theoretical "a priori" models, but relaxing the restrictive "independent clusters assumption" (i.e., all the items have just one loading on the respective factor, and no secondary loadings on different factors; see Morin, Marsh, \& Nagengast, 2013). This point 
is important in light of previous studies, suggesting a tendency for items included in motivational measures, to load on more than a single factor (Guay, Morin, Litalien, Valois, \& Vallerand 2015; Howard, Gagné, Morin, \& Forest, 2019 [Author: year is 2018 in references list. Please clarify]; Litalien, Guay, \& Morin, 2015).

In estimating all the parameters, we used the categorical variable estimator weighted least squares with mean- and variance-adjusted standard errors (WLSMV) over polychoric correlations (Rhemtulla, Brosseau-Liard, \& Savalei, 2012), as implemented in Mplus 8.3 (Muthén \& Muthén, 1998-2017). This estimator is considered to be more suited to the ordered-categorical nature of Likert-type scales than traditional maximum likelihood estimation (Beauducel \& Herzberg, 2006; Finney \& DiStefano, 2006; Guay et al., 2015).

Goodness of fit of the model was evaluated by inspecting the WLSMV-based $\chi^{2}$ statistic, the Comparative Fit Index (CFI), the Tucker Lewis Index (TLI), the Root Mean Square Error of Approximation (RMSEA), and the Weighted Root Mean Square Residual (WRMR). Values of RMSEA $<.06$ and CFI-TLI > .95 (Hu \& Bentler, 1999), as well as values of WRMR < 1 (DiStefano, Liu, Jiang, \& Shi, 2018) were considered acceptable. All the input files used for this and the other studies are presented in Electronic Supplementary Material, ESM 1.

\section{Reliability Analysis}

Reliability for each factor was computed using the nonlinear structural equation modeling reliability coefficient $\left(\rho_{\mathrm{NL}}\right)$, which is a reliability index appropriated for SEM with ordinal data (Garrido et al., in press [Author: please update]; Green \& Yang, 2009; Yang \& Green, 2015).

\section{Results}

\section{Descriptive Statistics}

Table 1 (see column Study 1) presents the $M s, S D s, \rho_{\mathrm{NL}}$, and corrected item-total correlation coefficients $\left(r_{\mathrm{tt}}\right)$ of each MAMS item. Mean scale scores ranged from 1.09 (Amotivation) to 4.55 (intrinsic motivation). On average, all items appeared strongly correlated with their respective scale score $\left(M_{r_{\mathrm{tt}}}=0.60, S D=0.11\right)$, with item-total scale score correlations ranging from .36 (Item 8) to .77 (Item 2). The $\rho_{\mathrm{NL}}$ ranged from .70 (identified regulation) to .86 (intrinsic regulation), thus attesting good reliability.

\section{Exploratory Structural Equation Modeling}

The hypothesized five-factor ESEM model provided a reasonable fit to the data, according to previously mentioned criteria: $\chi^{2}(61, N=452)=56.959, p=.623 ; \mathrm{CFI}=1.00$; $\mathrm{TLI}=1.00$; RMSEA $=.000,90 \%$ CI $[.000, .025], p=$ $1.00 ; \mathrm{WRMR}=.300$. All the factor loadings were high (see Table 2), ranging from .89 to .33 , with a mean of .73 $(S D=0.15)$. Latent factors were moderately to very highly correlated (see Table 3), with significant coefficients ranging from |.11| (amotivation with introjected regulation) to |.78| (amotivation with introjected regulation).

\section{Alternative Models}

The fit of the hypothesized five-factor ESEM model was compared with that of five alternative models, namely: (1) a CFA model with the five hypothesized factors, in which each item loaded onto the respective factor $\left[\chi^{2}(109, N=\right.$ $452)=271.770, p<.001 ; \mathrm{CFI}=.978 ; \mathrm{TLI}=.973$; RMSEA $=.059,90 \%$ CI $[.049, .066], p=.074 ; \mathrm{WRMR}=1.075]$; (2) a CFA model with three factors instead of five (amotivation, extrinsic regulation, and intrinsic regulation) in which the 9 items referring to the extrinsic regulation factors (i.e., external regulation, introjected regulation, and identified regulation) were specified as loading into just one single extrinsic regulation factor $\left[\chi^{2}(116, N=452)=883.813\right.$, $p<.001 ; \mathrm{CFI}=.905 ; \mathrm{TLI}=.889 ; \mathrm{RMSEA}=.121,90 \% \mathrm{CI}$ $[.114, .129], p>.001$; WRMR $=2.160]$; (3) a CFA bifactor model where the 9 items referring to the extrinsic regulation factors loaded simultaneously into three specific external regulation factors (i.e., external regulation, introjected regulation and identified regulation) and into a general extrinsic regulation factor $\left[\chi^{2}(107, N=452)=657.709\right.$, $p<.001 ; \mathrm{CFI}=.932 ;$ TLI $=.913 ;$ RMSEA $=.107,90 \%$ CI $[.099, .115], p>.001$; WRMR $=1.851]$; (4) a CFA hierarchical model in which the different factors of extrinsic motivation loaded into a single second-order factor $\left[\chi^{2}(113\right.$, $N=452)=768.456, p<.001 ; \mathrm{CFI}=.919 ; \mathrm{TLI}=.902$; RMSEA $=.113,90 \%$ CI $[.106, .121 p>.001$; WRMR $=$ 2.007]; (5) a CFA bifactor model where all the items loaded simultaneously into their respective specific regulation factors and into a general motivation factor (this last model was not identified).

Finally, the alternative models resulting in non-acceptable model fits were directly discarded (i.e., Models 2-3-4), while Model 1, that showed an acceptable data fit, was further examined. After this examination, it was also discarded because it resulted in correlations between the latent factors that were too high (i.e., > |.85|). At the end of this procedure, the initial ESEM solution, with five correlated factors, resulted as the best fitting one.

\section{Study 2}

In Study 2, using three different cohorts of cadets enrolled in the non-commissioned officers' school of Guardia di Finanza, we attempted to further confirm the MAMS fivefactor structure. Moreover, because previous studies demonstrated the existence of gender differences in 
Table 2. ESEM standardized factor loadings of each MAMS item - Study 1, Study 2, and Study 3

\begin{tabular}{|c|c|c|c|c|c|}
\hline Items & AMOT & EX & INTRJ & IDE & INTRI \\
\hline Item 3 & $.87 / .86 / .88$ & $-.04 / .03 / .11$ & $.04 / .06 / .18$ & $.01 / .01 /-.15$ & $-.07 /-.02 / .09$ \\
\hline Item 7 & $.89 / .93 / .78$ & $-.04 /-.11 / .15$ & $.02 / .00 / .01$ & $.12 / .13 /-.01$ & $-.09 /-.09 /-.15$ \\
\hline Item 10 & $.79 / .86 / .74$ & $.08 / .05 / .05$ & $-.03 / .03 /-.02$ & $-.05 /-.09 /-.03$ & $-.04 / .00 /-.25$ \\
\hline Item 15 & $.73 / .94 / .73$ & $.15 / .10 / .12$ & $.01 /-.02 / .03$ & $-.19 /-.13 /-.07$ & $-.10 / .07 /-.24$ \\
\hline Item 5 & $.07 / .10 / .14$ & $.61 / .69 / .88$ & $.20 / .10 /-.06$ & $.23 / .16 / .13$ & $-.06 / .00 /-.01$ \\
\hline Item 12 & $-.03 / .05 / .33$ & $.88 / .77 / .53$ & $.08 /-.04 / .04$ & $-.03 / .11 / .16$ & $-.08 /-.08 / .05$ \\
\hline Item 17 & $.10 /-.04 /-.09$ & $.64 / .48 / .34$ & $-.07 / .00 / .46$ & $-.07 /-.16 / .24$ & $.21 / .01 /-.19$ \\
\hline Item 4 & $-.11 / .03 / .27$ & $.20 / .12 / .11$ & $.69 / .61 / .54$ & $-.02 / .08 / .14$ & $-.06 / .00 / .14$ \\
\hline Item 11 & $-.08 / .08 / .18$ & $.10 /-.02 /-.09$ & $.82 / .83 / .81$ & $.06 / .08 / .14$ & $-.12 / .02 / .04$ \\
\hline Item 16 & $.27 / .03 /-.18$ & $-.03 / .03 / .23$ & $.68 / .73 / .81$ & $.07 / .05 /-.08$ & $.24 / .02 /-.06$ \\
\hline Item 6 & $.01 /-.01 /-.01$ & $.01 / .08 / .20$ & $-.04 /-.08 /-.01$ & $.60 / .63 / .46$ & $.25 / .25 / .33$ \\
\hline Item 8 & $.00 /-.07 /-.11$ & $-.15 /-.07 / .12$ & $.30 / .37 / .31$ & $.33 / .43 / .38$ & $.01 /-.03 / .07$ \\
\hline Item 9 & $-.07 /-.05 /-.19$ & $.14 / .14 / .15$ & $-.09 / .01 /-.03$ & $.86 / .81 / .95$ & $-.12 /-.06 /-.12$ \\
\hline Item 1 & $-.11 / .10 /-.25$ & $.05 /-.12 / .12$ & $-.09 /-.12 / .00$ & $.02 / .13 /-.09$ & $.80 / .89 / .77$ \\
\hline Item 2 & $-.12 /-.02 /-.26$ & $-.04 /-.14 / .16$ & $.04 /-.08 / .02$ & $-.08 / .10 /-.19$ & $.88 / .84 / .80$ \\
\hline Item 13 & $-.19 /-.09 /-.02$ & $-.07 / .08 /-.18$ & $.14 / .15 / .07$ & $.03 /-.11 / .11$ & $.61 / .78 / .82$ \\
\hline Item 14 & $.02 /-.06 / .12$ & $.03 / .13 /-.15$ & $-.03 / .11 /-.02$ & $.15 /-.05 / .25$ & $.80 / .83 / .83$ \\
\hline
\end{tabular}

Note. AMOT = Amotivation; EX = External Regulation; INTRJ = Introjected Regulation; IDE = Identified Regulation; INTRI = Intrinsic Regulation. Factor loadings of Study 1 appear before the first forward stash, factor loadings of Study 2 appear between the two forward stashes, and factor loadings of Study 3 appear after the second forward stash. Results in bold indicate the loadings of the items on their target a priori factor.

Table 3. Correlations among the MAMS factors - Study 1 and Study 2

414 motivation between males and females (Vecchione, 415 Alessandri, \& Marsicano, 2014), we investigated MAMS 416 measurement invariance across both gender and cohorts 417 (Meredith \& Teresi, 2006). This latter type of invariance 418 is important in order to track the evolution of achievement 419 motivation during the different academic stages (i.e., the 420 first, second, and third years).

\section{Method}

\section{Participants}

Participants of Study 2 were 1,372 military cadets attending the non-commissioned officers' school of the Guardia di Finanza. 827 were males $(60.3 \%)$ while 545 were females (39.7\%), and their ages ranged from 18 to 32 years $(M=$ 23.6, $S D=2.5)$. As in Study 1, the majority of participants had a high school degree $(1,163 ; 85 \%)$, whereas 209 $(15 \%)$ reported a university degree. Some of them also had previous experience in other military organizations
(428; $32.6 \%)$. The administration procedure was the same as in Study 1, and there were no missing data.

\section{Measures}

In this study, we administered the MAMS already described in detail in Study 1.

\section{Model Evaluation}

Model fit in single group analyses was evaluated following the same approach described in Study 1. Measurement invariance (for gender and cohort) was tested by fitting a sequence of increasingly restrictive models, in accordance with the guidelines suggested by Guay and colleagues (2015, Appendix C; see also Litalien et al., 2015). In the first (unconstrained) model, all factor loadings, thresholds, and error variances were allowed to differ across groups (configural invariance). In the second model (metric invariance), the factor loadings were constrained to be equal (i.e., equal $\lambda$ ). In the third model, we tested scalar invariance 
by imposing additional equality constraints on the thresholds (equal $\tau$ ). In the fourth model, we tested strict invariance by maintaining the restrictions of the previous steps, while imposing an additional constraint of equal item uniqueness (i.e., equal $\varepsilon$ ). If items' error variances are invariant across gender or cohorts, one can assume that items are equally reliable across gender or cohorts. Finally, in the fifth and sixth models, we imposed the patterns of variance and covariance of each MAMS factor to be equal across groups. Then, we fixed all the latent means to be equal across groups, respectively.

We considered measurement invariance supported if the fit of the restricted models did not decrease by more than .01 in CFI or increased by more than .015 in RMSEA (Chen, 2007). The theta parameterization was used for all invariance analyses. Differences among latent means were explored by fixing to zero the means of the reference group and allowing the means of the comparing groups to be freely estimated. The resulting values (in the unconstrained groups) represent the standardized distance of each group mean from the value of the reference group mean.

\section{Results}

\section{Descriptive Statistics}

Table 1 (see column Study 2) presents $M s, S D s, \rho_{\mathrm{NL}}$, and the corrected item-total correlation coefficients $\left(r_{\mathrm{tt}}\right)$ of each of the MAMS items. The values of these coefficients mimicked those found in Study 1. Indeed, mean scale scores ranged from 1.08 (Amotivation) to 4.55 (Intrinsic regulation), and all items appeared strongly correlated with their respective scale score $\left(M_{r_{\mathrm{tt}}}=0.62, S D=0.01 ; \min r_{\mathrm{tt}}=\right.$ .46 , item 8; $\max r_{\mathrm{tt}}=.73$, item 15). The $\rho_{\mathrm{NL}}$ ranged from .74 (external regulation) to .87 (amotivation), thus attesting good reliability.

\section{Exploratory Structural Equation Modeling}

As in Study 1, the hypothesized model provided an excellent fit to the data: $\chi^{2}(61, N=1,433)=137.679, p<.001 ; \mathrm{CFI}=$ .996; TLI $=.990$; RMSEA $=.030,90 \%$ CI [.024, .037], $p=$ 1.00; WRMR $=.458$ (Table 3). All the factor loadings were high (Table 2), ranging from .43 (item 8) to .94 (item 15; $M=0.76 ; S D=0.15)$. With regard to the correlation between the MAMS subscales, amotivation was positively related to external regulation and negatively related to intrinsic motivation (see Table 3). On the contrary, introjected regulation was correlated with external regulation and identified regulation, but uncorrelated with intrinsic regulation. These results nicely replicated those found in Study 1.

\section{Structure Validation Across Gender}

In examining the MAMS measurement invariance across gender, we started with testing the hypothesized model separately for males $\left[\chi^{2}(61, N=868)=93.705, p<.05\right.$; CFI $=.997$; TLI $=.993$; RMSEA $=.025,90 \%$ CI $[.014$, .035], $p=.693$; WRMR $=.366]$, and females $\left[\chi^{2}(61, N=\right.$ $565)=86.999, p<.05 ; \mathrm{CFI}=.996 ; \mathrm{TLI}=.992 ; \mathrm{RMSEA}=$ $.028,90 \%$ CI [.013, .041], $p=.999 ;$ WRMR $=.377]$. These models showed an acceptable fit. Loadings for these models were high, ranging from .48 (for item 8 , female group) to .96 (for item 15 , female group), with a mean of .70 ( $S D$ $=0.11$ ). Likewise, the configural model showed a good fit to the data, as well as the metric invariance model (for this and all the following comparisons refer to Table 3). All in all, metric, scalar, strict, and variance-covariance invariance were supported. To investigate mean level gender differences, we constrained latent means to be equal and found no significant differences $(\Delta \mathrm{CFI}=.000 ; \Delta \mathrm{RMSEA}=-.012)$.

\section{Structure Validation Across Cohorts}

The hypothesized model showed an acceptable fit across all the three cohorts considered (see Table 3). As shown in Table 3 , the configural, metric, and scalar invariance models resulted in a good fit to the data. Metric, scalar, and strict invariance were supported, but not the variance-covariance invariance. Therefore, in order to investigate mean level differences across cohorts, we constrained all the latent means to be equal, and compare this model with the strict one.

Results of the model comparison (Table 4) revealed some important differences among means: (1) the mean level of amotivation is higher in Cohort 3 than in Cohort $1(\Delta M=0.457)$, while there were no difference between Cohort 1 and Cohort 2; and (2) compared with the Cohort 1 , the mean levels of identified regulation and intrinsic regulation were lower in Cohort $2(\Delta M=-0.417$ and $\Delta M=$ -0.421 , respectively) and Cohort $3(\Delta M=-0.451$ and $\Delta M=-0.582$, respectively), while means of Cohort 2 and Cohort 3 were not significantly different. No other mean level difference was detected.

\section{Study 3}

In Study 3, the external validity of the MAMS was evaluated with respect to important organizational criteria, such as work engagement, burnout, organizational commitment, job performance, organizational citizenship behaviors (OCB), and intention to quit. The reasons for the selection of each of these constructs are explained below.

\section{Motivation and Work Engagement} ing in military contexts, is positively associated with 
Table 4. ESEM invariance for gender and cohorts - Study 2

\begin{tabular}{|c|c|c|c|c|c|c|c|c|c|c|c|}
\hline Model & $\chi^{2}$ & $d f$ & $\mathrm{CFI}$ & TLI & RMSEA & $\mathrm{Cl} 90 \%$ & WRMR & $\Delta \chi^{2}$ & $\Delta d f$ & $\Delta \mathrm{CFI}$ & $\triangle \mathrm{RMSEA}$ \\
\hline Total Sample & $137.679 \star \star \star$ & 61 & .996 & .990 & $.030^{\text {ns }}$ & {$[.024, .047]$} & .458 & & & & \\
\hline \multicolumn{12}{|c|}{ Cross-gender Invariance } \\
\hline Only male & $93.705 * \star *$ & 61 & .998 & .993 & $.025^{n s}$ & {$[.014, .035]$} & .366 & & & & \\
\hline Only female & $86.999 *$ & 61 & .996 & .992 & $.028^{n s}$ & {$[.013, .041]$} & .377 & & & & \\
\hline Configural & $180.286 * \star *$ & 122 & .997 & .993 & $.026^{n s}$ & {$[.018, .034]$} & .526 & & & & \\
\hline Metric & $222.224^{\star \star}$ & 182 & .998 & .997 & $.018^{\text {ns }}$ & {$[.007, .026]$} & .749 & $68.382^{\text {ns }}$ & 60 & .001 & -.008 \\
\hline Scalar & $267.526 *$ & 226 & .998 & .997 & $.016^{n s}$ & {$[.006, .024]$} & .864 & $55.978^{\text {ns }}$ & 44 & .000 & -.002 \\
\hline Strict & $320.343^{* * *}$ & 243 & .996 & .995 & $.022^{\text {ns }}$ & {$[.014, .028]$} & .994 & $51.999 * * *$ & 17 & -.002 & .006 \\
\hline Var-Cov & $282.380^{n s}$ & 258 & .999 & .999 & $.012^{\text {ns }}$ & {$[.000, .020]$} & 1.085 & $11.861^{n s}$ & 15 & .003 & -.010 \\
\hline Latent means & $282.452^{\text {ns }}$ & 263 & .999 & .999 & $.000^{n s}$ & {$[.000, .019]$} & 1.131 & $4.803^{n s}$ & 5 & .000 & -.012 \\
\hline \multicolumn{12}{|c|}{ Cross-cohorts invariance } \\
\hline Only Cohort 1 & $69.696^{\text {ns }}$ & 61 & .999 & .997 & $.016^{\text {ns }}$ & {$[.000, .031]$} & .340 & & & & \\
\hline Only Cohort 2 & $100.681 *$ & 61 & .994 & .989 & $.035^{n s}$ & {$[.022, .047]$} & .399 & & & & \\
\hline Only Cohort 3 & $68.783^{\text {ns }}$ & 61 & .999 & .997 & $.021^{\text {ns }}$ & {$[.000, .043]$} & .322 & & & & \\
\hline Configural & $240.897 * \star$ & 183 & .997 & .993 & $.026^{n s}$ & {$[.016, .035]$} & .623 & & & & \\
\hline Metric & $372.404 * \star$ & 303 & .996 & .995 & $.022^{\text {ns }}$ & {$[.013, .030]$} & 1.035 & $154.047 *$ & 120 & -.001 & -.004 \\
\hline Scalar & $485.147 * \star *$ & 377 & .994 & .993 & $.025^{n s}$ & {$[.018, .031]$} & 1.239 & $127.340 * * *$ & 74 & -.002 & .003 \\
\hline Strict & $630.670 * \star *$ & 411 & .988 & .988 & $.034^{n s}$ & {$[.029, .039]$} & 1.51 & $54.834 * * *$ & 34 & -.006 & .009 \\
\hline Var-Cov & $834.293 * \star *$ & 441 & .978 & .980 & $.044^{n s}$ & {$[.040, .049]$} & 2.410 & $133.480 * * *$ & 30 & -.010 & .010 \\
\hline Latent means & $999.155^{\star * *}$ & 451 & .969 & .972 & $.052^{n s}$ & {$[.047, .056]$} & 2.856 & $212.499 * * *$ & 40 & -.019 & .008 \\
\hline
\end{tabular}

Note. $\chi^{2}=$ Chi square statistics based on WLSMV estimation method; $d f=$ degree of freedom; CFI = Comparative Fit Index; RMSEA = Root Mean Square Error of Approximation; $\mathrm{Cl} 90 \%=$ Confidence Interval 90\%; WRMR = Weighted Root Mean Square Residual; $\Delta \chi^{2}=$ Chi square difference; $\Delta d f=$ degree of freedom difference; $\triangle \mathrm{CFI}=\mathrm{CFI}$ difference; $\triangle \mathrm{RMSEA}=\mathrm{RMSEA}$ difference. "The fit of the mean invariance model for cohort invariance was compared to the fit of the strict invariance model, as the invariance of the latent variance-covariance matrix was not supported. $\left.{ }^{\star} p<.05 ;{ }^{*} p<.01 ;{ }^{* \star} p<.001 ;{ }^{n s} p\right\rangle .05$.

self-determined forms of motivation and negatively correlated with more controlled forms of motivation (Chambel et al., 2015; Meyer, 2014; Meyer \& Gagnè, 2008). Therefore, we hypothesized that the more intrinsic motivation subscales of the MAMS, namely intrinsic motivation and identified motivation, were positively correlated with work engagement. Conversely, we did not expect positive relations between work engagement, amotivation, and the non-self-determined forms of motivation. More in detail, the higher negative correlation is expected with the lack of any motivation, namely amotivation. In sum, we expected that the relations between work engagement and the different types of motivation followed their relative positions on the self-determination continuum, going from the more negative (i.e., with amotivation) to the more positive (i.e., with intrinsic motivation).

\section{Motivation and Job Burnout}

In accordance with SDT propositions, burnout and its dimensions (i.e., emotional exhaustion, cynicism, and interpersonal strain ${ }^{1}$ ) should correlate stronger with the behavioral regulation styles at the end of the continuum (i.e., amotivation and intrinsic motivation) compared with the ones in the middle (i.e., introjected and identified regulation). Indeed, previous research has shown that the more non-self-determined forms of motivations positively correlated with burnout, whereas the more self-determined forms of motivation negatively correlated. (Chambel et al., 2015; Richer, Blanchard, \& Vallerand, 2002). In addition, as hypothesized by Lonsdale, Hodge, and Rose (2009), we expected that the relations between burnout and behavioral regulations varied consistently with their rank on the self-determination continuum. More in detail, we hypothesized that (1) amotivation, external regulation, and introjected regulation were positively correlated with burnout dimensions, with amotivation having the higher coefficient, while (2) identified regulation as well as intrinsic regulation were negatively correlated with burnout dimensions, with intrinsic regulation having the higher coefficient.

\section{Motivation and Organizational Commitment}

Allen and Meyer's three-component model of organizational commitment (1990) differentiates affective, normative, and continuance commitments. The first reflects the

\footnotetext{
${ }^{1}$ Data on the "reduced sense of accomplishment" dimension of job burnout were not collected because of the larger research purpose [Author: please integrate footnote into main text, if possible].
} 
emotional attachment to one's organization as well as the degree to which individuals perceive themselves identified with it (e.g., sense of belongingness). The second represents the feelings of obligation for one's organization (e.g., loyalty). Finally, the third results from the cost-benefit analysis of quitting the job (e.g., scarcity of job alternatives).

Importantly, the relations between the three components of commitment and the different forms of motivation postulated by SDT are empirically supported with individuals with a strong affective commitment characterized by more autonomous forms of regulation (i.e., intrinsic, identified), whereas those with a strong normative or continuance commitment are likely to experience more controlled forms of regulation (i.e., introjected or external; Meyer, Becker, \& Vandenberghe, 2004). However, all forms of extrinsic regulations can be source of motivation (Meyer et al., 2004) and the organizational commitment theory postulates that in highly controlling contexts (e.g., military organization), both the continuance and the normative components of commitment may be related with autonomous forms of motivation. Therefore, we hypothesized that (1) affective commitment showed the higher positive correlation with both intrinsic and identified regulation, and negatively related with the controlled forms of motivation, (2) continuance and normative commitments positively related with the autonomous forms of motivation and negatively with the non-self-determined forms of motivation.

\section{Motivation and Job Performance}

Previous studies have found that only autonomous forms of motivation were predictive of job performance (Deci \& Ryan, 2008; Grolnick \& Ryan, 1987; Grolnick, Ryan, \& Deci, 1991). Gagné and Deci (2005) suggested that identified motivation is associated with job performance for those tasks that are not very interesting. On the contrary, intrinsic motivation is associated with performance in self-set goals that are relevant for the individual. Accordingly, we hypothesized a positive association between job performance and intrinsic motivation. On the contrary, we expected that job performance showed (1) low or not-significant correlations with identified, (2) negative correlations with extrinsic motivation (i.e., introjected regulation, external regulation) and amotivation.

\section{Motivation and Organizational Citizenship Behaviors}

Organizational citizenship behaviors refer to a set of prosocial behavior exceeding the formal job requirements and contributing to the organizational effectiveness (Organ, 1998 [Author: year is $\mathbf{1 9 8 8}$ in references list. Please clarify]). Thus, people freely choose to act OCB in order to help others and not because they are constrained. Accordingly, previous studies, both cross-sectional and longitudinal, suggested a positive relationship between self-determined motivation and OCB (Gagné, 2003; Grant, 2008; Zhang
\& Chen, 2013). As for the linkage motivation-work engagement, we hypothesized that the relations between motivation and $\mathrm{OCB}$ followed the relative positions of the different types of motivation on the self-determination continuum, going from the more negative (i.e., with amotivation) to the more positive (i.e., with intrinsic motivation).

\section{Motivation and the Intention to Quit the Military Academy}

Several studies have addressed which forms of motivation are related to and/or predict intention to quit (i.e., turnover intention; Dysvik \& Kuvaas, 2010; Gillet, Gagné, Sauvagère, \& Fouquereau, 2013; Haivas, Hofmans, \& Pepermans, 2013). Relying on both SDT and empirical evidence linking SDT and turnover intentions, we hypothesized that (1) the autonomous forms of motivation, or intrinsic motives, were negatively related to turnover intention, whereas (2) the controlled forms of motivation are positively related to turnover intention. Importantly, the highest negative correlation of turnover intentions is expected with amotivation because it represents a maladaptive form of motivation strictly linked with dropping out (Deci \& Ryan, 1985).

\section{Method}

\section{Participants}

Participants in Study 3 were 520 military cadets attending the non-commissioned officers' school of the Guardia di Finanza. Three hundred eighteen were males $(61 \%)$ while 202 were females (39\%); their ages ranged from 18 to 31 years $(M=22.9, S D=2.5)$. As in Studies 1 and 2, most of participants had a high school degree $(436 ; 84 \%)$, whereas $84(16 \%)$ had a university degree. There were also participants with previous experience in another military organization $(146 ; 28 \%)$. The administration procedure was the same as in Studies 1 and 2. There were no missing data.

\section{Measures}

In this study, we administered the MAMS already described in detail in previous Studies, as well as the following scales. We used the coefficient omega $(\omega)$, derived by a matrix of polychoric correlations, to evaluate the score reliabilities for each of the following scales (Zinbarg, Revelle, Yovel, \& Li, 2005). This coefficient is analogous to Cronbach's alpha $(\alpha)$, but it is more appropriate for a set of congeneric items (Zinbarg et al., 2005).

Work Engagement $(\omega=.96)$

We used the 17-item Utrecht Work Engagement Scale (UWES-17; Schaufeli, Salanova, González-Romá, \& Bakker, 2002) to assess cadets' work engagement (response scale: $0=$ never $; 6$ always). 
Burnout Dimensions (Response Scale: $0=$ Never; $6=$ Every Day)

Emotional exhaustion $(\omega=.89)$, and Cynicism $(\omega=.91)$ were measured by five items from the Maslach Burnout Inventory - General Survey (MBI-GS; Maslach, Jackson, \& Leiter, 1996). Interpersonal strain $(\omega=.96)$ was measured with the 5-item Interpersonal Strain at Work Scale (ISW; Borgogni, Consiglio, Alessandri, \& Schaufeli, 2012).

\section{Organizational Commitment}

Affective commitment (7 items, $\omega=.91$ ), Continuance commitment (4 items, $\omega=.62$ ) and Normative commitment (4 items, $\omega=.62$ ) were measured by the scale proposed by Allen and Meyer (1990). The response ranged from (response scale): 1 = strongly disagree; 7 = strongly agree.

Job Performance (7 Items; $\omega=.89$ )

Task performance was assessed with the self-report scale developed by Williams and Anderson (1991). Response scale used was: $1=$ strongly disagree to $5=$ strongly agree).

\section{Organizational Citizenship Behaviors}

Extra-role behaviors (1) directed to benefit a colleague (OCBI; 7 items; $\omega=.85$ ), or (2) to benefit the entire organization (OCBO; 7 items; $\omega=.76$ ) were assessed by using the self-report scale introduced by Williams and Anderson (1991; response scale: 1 = strongly disagree; $5=$ strongly agree).

Intention to Quit (2 Items; $\omega=.87$ )

Intention to quit was measured by two items (i.e., "How likely is it that you will leave your job in the next 12 months?"; "I want to leave my work") drawn from the Michigan Organizational Assessment Questionnaire (response scale: 1 = very unlikely; 5 very likely) and adapted for use in the present military academy context (Cammann, Fichman, Jenkins, \& Klesh, 1979).

\section{Results}

Before analyzing the correlations between the MAMS scales and the aforementioned constructs, we retested the empirical fit of the hypothesized five-factor structure of the MAMS using ESEM as well as the previous Studies. Again, the model provided a good fit to the data: $\chi^{2}(61, N=520)=$ $130.260, p<.001$; CFI $=.996$; TLI $=.990$; RMSEA $=.047$, $90 \%$ CI [.036, .058], $p=.669$; WRMR $=.472$. Furthermore, as presented in Table 1, the $\rho_{\mathrm{NL}}$ ranged from .81 (identified regulation) to .91 (amotivation), thus attesting good reliability, and as presented in Table 2, factor loadings (ranging from .34 to $.95 ; M=0.71, S D=0.18$ ) were acceptable for each scale. Consistent with Studies 1 and 2, all items appeared strongly correlated with their respective scale score $\left(M_{r_{\mathrm{tt}}}=0.67, S D=0.09\right)$, with item-total scale score correlations ranging from .45 to .79 . These results contributed further to the validity of the internal structure of the MAMS.

\section{Correlations}

Overall, all correlations presented in Table 5 between the MAMS scales among them and with the other constructs were in the expected direction. The correlations between the MAMS scales mimicked those of Studies 1 and 2 (upper part of Table 5). Furthermore, intrinsic regulation was strongly related to work engagement, while amotivation was negatively associated with work engagement. Amotivation and external motivation were both significantly and positively correlated with emotional exhaustion, cynicism, and interpersonal strain. At the same time, intrinsic regulation was positively and significantly correlated to job performance, OCBI, and OCBO. Affective commitment was strongly related to intrinsic regulation, while continuance commitment and normative commitment were moderately correlated to intrinsic regulation, and identified regulation. Introjected regulation, on the other hand, was correlated with continuance commitment. Finally, intention to quit was strongly and positively related to amotivation, and negatively related to intrinsic regulation.

\section{Discussion}

In a demanding and challenging environment, such as military academies and schools, individuals need to work very hard in order to fulfill expectations. To this aim, cadets need to be strongly motivated in order to find the energy to persist and continue in the face of adversities, despite discouragement and obstacles. Thus, it is imperative to understand the different forms of motivation animating cadets, in order to better support and help them when entering the academy or school. For that reason, the availability of an instrument able to reliably assess different forms of motivation, as manifested in the military context, is of great importance.

In this paper, we introduced the MAMS, an instrument intended to measure different forms of motivation according to the SDT. The results of three independent studies provided proof of its reliability, as well as internal and external validity. The availability of a brief and reliable instrument such as the MAMS is important in order to individuate cadets animated by more autonomous forms of motivation (above all, intrinsic motivation), who are less exposed to organizational risks and more likely to succeed in their work. For instance, a comprehensive meta-analytic study by Cerasoli et al. (2014) found that intrinsic motivation remained a significant predictor of performance, even 
Table 5. Correlation matrix - Study 3

\begin{tabular}{|c|c|c|c|c|c|}
\hline & AMOT & EX & INTRJ & IDE & |NTRI \\
\hline AMOT & - & & & & \\
\hline EX & $.30 * \star \star$ & - & & & \\
\hline INTRJ & $.19 * \star \star$ & $.71 * \star \star$ & - & & \\
\hline IDE & -.01 & $.58 * \star \star$ & $.60 * \star \star$ & - & \\
\hline INTRI & 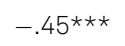 & $-.13 * \star$ & .01 & $.27 * \star \star$ & - \\
\hline Work Engagement & $-.43 * \star \star$ & $-.20 * \star *$ & -.06 & $.16 * \star \star$ & $.70 * * *$ \\
\hline Emotional Exhaustion & $.40 * \star \star$ & $.28 * \star *$ & $.16 * \star \star$ & -.05 & $-.54 * \star \star$ \\
\hline Cyniscism & $.58 \star \star \star$ & $.26 * \star \star$ & 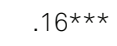 & -.05 & $-.61 \star \star \star$ \\
\hline Interpersonal Strain & $.63 * \star \star$ & $.26 * \star \star$ & $.16 * \star \star$ & -.07 & $-.61 \star \star \star$ \\
\hline Affective Commitment & $-.41 * \star \star$ & $-.15 * \star *$ & -.03 & 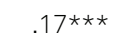 & $.68 * * \star$ \\
\hline Continuance Commitment & $-.20 * * \star$ & .09 & $.15 * \star *$ & $.25 * \star \star$ & $.29 * * *$ \\
\hline Normative Commitment & $-.19 * \star \star$ & -.02 & .05 & $.23 * \star \star$ & $.45 * \star \star$ \\
\hline Performance & $-.50 * \star \star$ & $-.22 * \star \star$ & $-.09 *$ & $.13 * \star$ & $.62 * \star \star$ \\
\hline OCBI & $-.20 * \star \star$ & $-.12 \star \star$ & & $.14^{\star *}$ & $.49 * \star *$ \\
\hline OCBO & $-.54 * \star \star$ & $-.23 * \star \star$ & & $.09 *$ & $.58 * \star \star$ \\
\hline Intention to Quit & $.71 * \star \star$ & $.16 * \star \star$ & .08 & -.07 & $-.48 * \star \star$ \\
\hline
\end{tabular}

Note. AMOT = Amotivation; EX = External Regulation; INTRJ = Introjected Regulation; IDE $=\mid$ dentified Regulation; INTRI $=\mid$ Intrinsic Regulation. ${ }^{\star} p<.05 ;{ }^{*} p<$ $.01 ;{ }^{* *} p<.001$.

after controlling for extrinsic incentives, and a narrative review by Deci, Olafsen, and Ryan (2017) concluded that "autonomous motivation predicted less burnout, work exhaustion, and turnover, as well as greater work satisfaction, work commitment, and performance, whereas controlled motivation has tended to show opposite results" (p. 25).

\section{Internal and External Validity}

More in detail, the internal validity of the MAMS has been corroborated in three studies, and its measurement invariance (across gender and cohorts) and external validity has been attested in Study 2 and Study 3, respectively. Results regarding measurement invariance are important because one of the applications of the MAMS would be that of reliably ranking individuals by their different motivational levels regardless of their gender or year of course. Given that our results showed that the MAMS remains invariant across gender and cohorts, MAMS may be considered suitable for this aim.

Furthermore, correlations with other work-related variables confirmed the external validity of each MAMS factor. More in detail, the significant correlations with work engagement and OCB support the link between self-determined forms of motivation and indices of adjustment at work, as already demonstrated (Chambel et al., 2015; Meyer, 2014; Meyer \& Gagnè, 2008). On the contrary, the correlations between amotivation and external regulation with burnout underlined the potentially noxious effect of those forms of motivations for workers. It is likely that people who do not invest in their work or people who feel constrained to invest in works they do not like may, in the long run, be more exposed to the risk of developing work-related stress symptoms.

Moreover, the negative correlations of amotivation with $\mathrm{OCB}$ and job performance further confirm what is theoretically expected, namely that amotivated workers are unwilling to make unnecessary investments in their work. Unsurprisingly, workers showing higher levels of identified regulation and intrinsic regulation had higher scores on job performance and higher levels of affective commitment. The more workers are animated at work by an internalized form of motivation, the higher is their expected level of performance. Moreover, from a theoretical point of view, being affectively committed to ones' own work requires a personal investment that is likely to be made only by individuals with high levels of autonomous motivation.

The correlation between intrinsic regulation with normative commitment and continuance commitment are worth of special consideration. Attending a military academy exerts a strong transformative effect on the individual personality (Soeters, 2018). Thus, leaving the academy is associated with an onerous cost for the subject that, along with the waste of time and energy, may present difficulties when reentering civil society, an event that requires him/her to restructure his/her identity, accordingly. Ultimately, these results suggest that cadets have a great identification with the military organization. In fact, normative commitment 
and continuance commitment were not related to external regulation, suggesting that the cadet's willingness to not leave the academy is independent from the external rewards they could receive for their job.

Finally, we found an overall confirmation for the correlations between organizational criteria and the different forms of motivation included in the MAMS. However, we observed some unexpected nonsignificant correlations. First, introjected regulation was not related to work engagement, OCBI, and affective and normative commitment. In addition, neither introjected regulation nor identified regulation was related to intention to quit. All these results need to be investigated more deeply in future research on military context. In any case, the overall pattern of correlations provided good evidence of construct validity for each MAMS factor.

\section{Mean Level Differences}

Of importance, we found no significant differences between males and females in the levels of different motivations. Instead, there was a significant increase in amotivation from Cohort 1 to Cohort 3, and a decrease of intrinsic regulation from Cohort 1 to Cohort 2 and Cohort 3. The same decline was observed for identified regulation. It is likely that over time, the very hard and tiring training that cadets must face during the academic years have a deteriorating effect on their motivation. As cadets move forward into the military academy life, they revise their motivations, making them more realistically attuned with their experience of the hard work required to have success in the academy and to become a full member of the military.

\section{Limitations}

This study has many strengths, such as the replication of results across the studies, the use of large sample sizes, and the broad range of external criteria considered. However, it also has several limitations that should be acknowledged. For example, the samples, although representative, were recruited from a single national context and a single military context. Thus, the generality of our results across cultures and military settings is a point to be addressed in future studies. Furthermore, the psychometric properties of the MAMS were analyzed using only cross-sectional data. Future studies might test the longitudinal stability of the MAMS across time.

\section{Conclusions}

Over the years, the study of work motivation through the lens of SDT has attracted considerable interest. In this paper, we provided initial evidence for the validity of a new SDT-based assessment instrument, namely the MAMS. Our hope is that our contribution will advance the empirical literature regarding the motivational forces driving the behavior of cadets in the specific and challenging phase of their initial military training. Most importantly, we hope that researchers will find inspiration in our work to examine the psychometric properties of the MAMS in other different samples.

\section{Electronic Supplementary Material}

The electronic supplementary material is available with the online version of the article at https://doi.org/ 10.1027/1015-5759/a000593

ESM 1. Input and output data for the studies [Author: ok?]

\section{References}

Allen, N. J., \& Meyer, J.P. (1990). The measurement and antecedents of affective, continuance and normative commitment to the organization. Journal of Occupational Psychology, 63, 1-18. https://doi.org/10.1111/j.2044-8325.1990.tb00506.x Beauducel, A., \& Herzberg, P. Y. (2006). On the performance of maximum likelihood versus means and variance adjusted weighted least squares estimation in CFA. Structural Equation Modeling, 13, 186-203. https://doi.org/10.1207/s15328007sem1302_2

Borgogni, L., Consiglio, C., Alessandri, G., \& Schaufeli, W. B. (2012). "Do throw the baby out with the bathwater!" Interpersonal strain at work and burnout. European Journal of Work and Organizational Psychology, 21, 875-898. https://doi.org/ 10.1080/1359432X.2011.598653

Caforio, G. (2018). Military officer education. In G. Caforio \& M. Nuciari (Eds.), Handbook of the sociology of the military (2nd ed., pp. 251-272). Cham, Switzerland: Springer International.

Caforio, G., \& Nuciari, M. (1994). The officer profession: Ideal-type. Current Sociology, 42, 33-56. https://doi.org/10.1177/ 001139294042003005

Cammann, C., Fichman, M., Jenkins, D., \& Klesh, J. (1979). The Michigan organizational assessment questionnaire (Unpublished manuscript). Ann Arbor, MI: University of Michigan.

Cerasoli, C. P., Nicklin, J. M., \& Ford, M.T. (2014). Intrinsic motivation and extrinsic incentives jointly predict performance: A 40-year meta-analysis. Psychological Bulletin, 140, 9801008. https://doi.org/10.1037/a0035661

Chambel, M. J., Castanheira, F., Oliveira-Cruz, F., \& Lopes, S. (2015). Work context support and Portuguese soldiers' wellbeing: The mediating role of autonomous motivation. Military Psychology, 27, 297-310. https://doi.org/10.1037/mil0000087

Chan, D. K. C., Webb, D., Ryan, R. M., Tang, T. C. W., Yang, S. X., Ntoumanis, N., \& Hagger, M. S. (2017). Preventing occupational injury among police officers: Does motivation matter? Occupational Medicine, 67, 435-441. https://doi.org/10.1093/occmed/ kqx076

Chen, F. F. (2007). Sensitivity of goodness of fit indexes to lack of measurement invariance. Structural Equation Modeling, 14, 464-504. https://doi.org/10.1080/10705510701301834
901

886

887

888

889

890

891

892

893

894 
Cheung, G. W., \& Rensvold, R. B. (2002). [Author: add in-text citation or delete reference]Evaluating goodness-of-fit indexes for testing measurement invariance. Structural Equation Modeling, 9, 233-255. https://doi.org/10.1207/ S15328007SEM0902_5

Cokley, K. O. (2000). [Author: add in-text citation or delete reference] Examining the validity of the Academic Motivation Scale by comparing scale construction to self-determination theory. Psychological Reports, 86, 560-564. https://doi.org/ 10.2466/pr0.2000.86.2.560

Dahlman, C. J. (2007). The cost of a military person-year: A method for computing savings from force reductions. Santa Monica, CA: RAND.

Deci, E. L., Olafsen, A. H., \& Ryan, R. M. (2017). Self-determination theory in work organizations: The state of a science. Annual Review of Organizational Psychology and Organizational Behavior, 4. [Author: add page range]https://doi.org/10.1146/annurev-orgpsych-032516-113108

Deci, E. L., \& Ryan, R. M. (1985). Intrinsic motivation and selfdetermination in human behavior. New York, NY: Plenum Press.

Deci, E. L., \& Ryan, R. M. (2008). Self-determination theory: A macrotheory of human motivation, development, and health. Canadian Psychology, 49, 182-185. https://doi.org/10.1037/ a0012801

DiStefano, C., Liu, J., Jiang, N., \& Shi, D. (2018). Examination of the weighted root mean square residual: Evidence for trustworthiness? Structural Equation Modeling, 25, 453-466. https://doi. org/10.1080/10705511.2017.1390394

Dysvik, A., \& Kuvaas, B. (2010). Exploring the relative and combined influence of mastery-approach goals and work intrinsic motivation on employee turnover intention. Personnel Review, 39, 622-638. https://doi.org/10.1108/ 00483481011064172

Fairchild, A. J., Horst, S. J., Finney, S. J., \& Barron, K. E. (2005). [Author: add in-text citation or delete reference]Evaluating existing and new validity evidence for the Academic Motivation Scale. Contemporary Educational Psychology, 30, 331-358. https://doi.org/10.1016/j.cedpsych.2004.11.001

Finney, S. J., \& DiStefano, C. G. (2006). Non-normal and categorical data in structural equation modeling. In G. R. Hancock \& R. O. Mueller (Eds.), Structural equation modeling: A second course (pp. 269-314). Greenwich, CT: Information Age.

Gagné, M. (2003). The role of autonomy support and autonomy orientation in prosocial behavior engagement. Motivation and Emotion, 27, 199-223. https://doi.org/10.1023/ A:1025007614869

Gagné, M., \& Deci, E. L. (2005). Self-determination theory and work motivation. Journal of Organizational Behavior, 26, 331362. https://doi.org/10.1002/job.322

Gagné, M., Forest, J., Vansteenkiste, M., Crevier-Braud, L., van den Broeck, A., Aspeli, A. K., ... Westbye, C. (2015). The Multidimensional Work Motivation Scale: Validation evidence in seven languages and nine countries. European Journal of Work and Organizational Psychology, 24, 178-196. https://doi.org/ 10.1080/1359432X.2013.877892

Garrido, L. E., Barrada, J. R., Aguasvivas, J. A., Martínez-Molina, A., Arias, V. B., Golino, H. F., ... Rojo-Moreno, L. (in press). [Author: please update] Is small still beautiful for the Strengths and Difficulties Questionnaire? Novel findings using Exploratory Structural Equation Modeling. Assessment. https://doi.org/ 10.1177/1073191118780461

Gibb, G. D., \& Dolgin, D. L. (1988). Factors affecting career retention among naval aviators. Journal of Business and Psychology, 2, 321-326. https://doi.org/10.1007/BF01013764

Gillet, N., Gagné, M., Sauvagère, S., \& Fouquereau, E. (2013). The role of supervisor autonomy support, organizational support, and autonomous and controlled motivation in predicting employees' satisfaction and turnover intentions. European Journal of Work and Organizational Psychology, 22, 450-460. https://doi.org/10.1080/1359432X.2012.665228

Gillet, N., Huart, I., Colombat, P., \& Fouquereau, E. (2013). Perceived organizational support, motivation, and engagement among police officers. Professional Psychology: Research and Practice, 44, 46-55. https://doi.org/10.1037/a0030066

Grant, A. M. (2008). Does intrinsic motivation fuel the prosocial fire? Motivational synergy in predicting persistence, performance, and productivity. Journal of Applied Psychology, 93, 4858. https://doi.org/10.1037/0021-9010.93.1.48

Green, S. B., \& Yang, Y. (2009). Reliability of summed item scores using structural equation modeling: An alternative to coefficient alpha. Psychometrika, 74, 155-167. https://doi.org/ 10.1007/s11336-008-9099-3

Grolnick, W. S., \& Ryan, R. M. (1987). Autonomy in children's learning: An experimental and individual difference investigation. Journal of Personality and Social Psychology, 52, 890-898. https://doi.org/10.1037/0022-3514.52.5.890

Grolnick, W. S., Ryan, R. M., \& Deci, E. L. (1991). Inner resources for school achievement: Motivational mediators of children's perceptions of their parents. Journal of Educational Psychology, 83, 508-517. https://doi.org/10.1037/0022-0663. 83.4.508

Grouzet, F. M. E., Otis, N., \& Pelletier, L. G. (2006). Longitudinal cross-gender factorial invariance of the Academic Motivation Scale. Structural Equation Modeling, 13, 73-98. https://doi.org/ 10.1207/s15328007sem1301_4

Guay, F., Morin, A. J., Litalien, D., Valois, P., \& Vallerand, R. J. (2015). Application of exploratory structural equation modeling to evaluate the academic motivation scale. The Journal of Experimental Education, 83, 51-82. https://doi.org/10.1080/ 00220973.2013 .876231

Haivas, S., Hofmans, J., \& Pepermans, R. (2013). Volunteer engagement and intention to quit from a self-determination theory perspective. Journal of Applied Social Psychology, 43, 1869-1880. https://doi.org/10.1111/jasp.12149

Hall, L. K. (2011). The importance of understanding military culture. Social Work in Health Care, 50, 4-18. https://doi.org/ 10.1080/00981389.2010.513914

Howard, J. L., Gagné, M., Morin, A. J., \& Forest, J. (2018). [Author: year is 2019 in text. Please clarify] Using bifactor exploratory structural equation modeling to test for a continuum structure of motivation. Journal of Management, 44, 2638-2664. https:// doi.org/10.1177/0149206316645653

Hu, L. T., \& Bentler, P. M. (1999). Cutoff criteria for fit indexes in covariance structure analysis: Conventional criteria versus new alternatives. Structural Equation Modeling, 6, 1-55. https://doi. org/10.1080/10705519909540118

Kanfer, R., Frese, M., \& Johnson, R. E. (2017). Motivation related to work: A century of progress. Journal of Applied Psychology, 102, 338-355. https://doi.org/10.1037/apl0000133

Litalien, D., Guay, F., \& Morin, A. J. (2015). Motivation for PhD studies: Scale development and validation. Learning and Individual Differences, 41, 1-13. https://doi.org/10.1016/j. lindif.2015.05.006

Lonsdale, C., Hodge, K., \& Rose, E. (2009). Athlete burnout in elite sport: A self-determination perspective. Journal of sports sciences, 27, 785-795. https://doi.org/10.1080/ 02640410902929366

Marsh, H. W., Morin, A. J., Parker, P. D., \& Kaur, G. (2014). Exploratory structural equation modeling: An integration of the best features of exploratory and confirmatory factor analysis. Annual Review of Clinical Psychology, 10, 85-110. https://doi.org/10.1146/annurev-clinpsy-032813-153700 
1074

1075

1076

1077

1078

1079

1080

1081

1082

1083

1084

1085

1086

1087

1088

1089

1090

1091

1092

1093

1094

1095

1096

1097

1098

1099

1100

1101

1102

1103

1104

1105

1106

1107

1108

1109

1110

1111

1112

1113

1114

1115

1116

1117

1118

1119

1120

1121

1122

1123

1124

1125

1126

1127

1128

1129

1130

1131

1132

1133

1134

1135

1136

1137
Maslach, C., Jackson, S. E., \& Leiter, M.P. (1996). Maslach Burnout Inventory manual. Palo Alto, CA: Consulting Psychologist Press.

Meredith, W., \& Teresi, J. A. (2006). An essay on measurement and factorial invariance. Medical Care, 44, 69-77. https://doi.org/ 10.1097/01.mlr.0000245438.73837.89

Meyer, J.P. (2014). Employee commitment, motivation, and engagement: Exploring the links. In M. Gagné (Ed.), The Oxford handbook of work engagement, motivation, and self-determination theory (pp. 33-49). New York, NY: Oxford University Press.

Meyer, J. P., Becker, T. E., \& Vandenberghe, C. (2004). Employee commitment and motivation: A conceptual analysis and integrative model. Journal of Applied Psychology, 89, 991-1007. https://doi.org/10.1037/0021-9010.89.6.991

Meyer, J. P., \& Gagnè, M. (2008). Employee engagement from a self-determination theory perspective. Industrial and Organizational Psychology, 1, 60-62. https://doi.org/10.1111/j.17549434.2007.00010.x

Morin, A. J. S., Marsh, H. W., \& Nagengast, B. (2013). Exploratory structural equation modeling. In G. R. Hancock \& R. O. Mueller (Eds.), Structural equation modeling: A second course (2nd ed., pp. 395-436). Charlotte, NC: Information Age.

Muthén, L. K., \& Muthén, B. O. (1998-2017). Mplus user's guide (8th ed.). Los Angeles, CA: Muthén \& Muthén.

Organ, D. W. (1988). [Author: year is 1998 in text. Please clarify] Organizational citizenship behavior: The good soldier syndrome. Lexington, MA: Lexinton Books.

Otis, N., Grouzet, F. M., \& Pelletier, L. G. (2005). Latent motivational change in an academic setting: A 3-Year longitudinal study. Journal of Educational Psychology, 97, 170-183. https:// doi.org/10.1037/0022-0663.97.2.170

Otis, N., \& Pelletier, L. G. (2005). A motivational model of daily hassles, physical symptoms, and future work intentions among police officers. Journal of Applied Social Psychology, 35, 21932214. https://doi.org/10.1111/j.1559-1816.2005.tb02215.x

Ratelle, C. F., Guay, F., Larose, S., \& Senécal, C. (2004). Family correlates of trajectories of academic motivation during a school transition: A semiparametric group-based approach. Journal of Educational Psychology, 96, 743-754. https://doi. org/0.1037/0022-0663.96.4.743

Rhemtulla, M., Brosseau-Liard, P. É., \& Savalei, V. (2012). When can categorical variables be treated as continuous? A comparison of robust continuous and categorical SEM estimation methods under suboptimal conditions. Psychological Methods, 17, 354-373. https://doi.org/10.1037/a0029315

Richer, S. F., Blanchard, C., \& Vallerand, R. J. (2002). A motivational model of work turnover. Journal of Applied Social Psychology, 32, 2089-2113. https://doi.org/10.1111/j.15591816.2002.tb02065.x

Ryan, R. M., \& Connell, J. P. (1989). [Author: add in-text citation or delete reference] Perceived locus of causality and internalization: Examining reasons for acting in two domains. Journal of Personality and Social Psychology, 57, 749-761. https://doi. org/10.1037/0022-3514.57.5.749

Ryan, R. M., \& Deci, E. L. (2000). Self-determination theory and the facilitation of intrinsic motivation, social development, and well-being. American Psychologist, 55, 68-78. https://doi.org/ 10.1037110003-066X.55.1.68

Ryan, R. M., \& Deci, E. L. (2017). Self-determination theory: Basic psychological needs in motivation, development, and wellness. New York, NY: Guilford Press.

Schaufeli, W. B., Salanova, M., González-Romá, V., \& Bakker, A. B. (2002). The measurement of engagement and burnout: A two sample confirmatory factor analytic approach. Journal of
Happiness Studies, 3, 71-92. https://doi.org/10.1023/ A:1015630930326

Segal, M. W. (1986). The military and the family as greedy institutions. Armed Forces \& Society, 13, 9-38. https://doi. org/10.1177/0095327X8601300101

Soeters, J. (2018). Organizational cultures in the military. In G. Caforio \& M. Nuciari (Eds.), Handbook of the sociology of the military (2nd ed., pp. 251-272). Cham, Switzerland: Springer International.

Vallerand, R. J., Blais, M. R., Brière, N. M., \& Pelletier, L. G. (1989). Construction et validation de l'échelle de motivation enéducation (EME) [Construction and validation of the Motivation toward Education Scale]. Canadian Journal of Behavioural Science/Revue Canadienne Des Sciences Du Comportement, 21, 323-349. https://doi.org/10.1037/h0079855

Vallerand, R. J., Pelletier, L. G., Blais, M. R., Briere, N. M., Senecal, C., \& Vallieres, E. F. (1992). The Academic Motivation Scale: A measure of intrinsic extrinsic and amotivation in education. Educational and Psychological Measurement, 52, 1003-1017. https://doi.org/10.1177/0013164492052004025

Vallerand, R. J., Pelletier, L. G., Blais, M. R., Briere, N. M., Senecal, C., \& Vallieres, E. F. (1993). On the assessment of intrinsic, extrinsic, and amotivation in education: Evidence on the concurrent and construct validity of the Academic Motivation Scale. Educational and Psychological Measurement, 53(1), 159172. https://doi.org/10.1177/0013164493053001018

Vecchione, M., Alessandri, G., \& Marsicano, G. (2014). Academic motivation predicts educational attainment: Does gender make a difference? Learning and Individual Differences, 32, 124-131. https://doi.org/10.1016/j.lindif.2014.01.003

Yang, Y., \& Green, S. B. (2015). Evaluation of structural equation modeling estimates of reliability for scales with ordered categorical items. Methodology, 11, 23-34. https://doi.org/ 10.1027/1614-2241/a000087

Williams, L. J., \& Anderson, S. E. (1991). Job satisfaction and organizational commitment as predictors of organizational citizenship and in-role behaviors. Journal of Management, 17 , 601-617. https://doi.org/10.1177/014920639101700305

Zhang, Y., \& Chen, C. C. (2013). Developmental leadership and organizational citizenship behavior: Mediating effects of selfdetermination, supervisor identification, and organizational identification. Leadership Quarterly, 24, 534-543. https://doi. org/10.1016/j.leaqua.2013.03.007

Zinbarg, R. E., Revelle, W. R., Yovel, I., \& Li, W. (2005). Cronbach's, a Revelle's $\beta$ and McDonald's $\omega_{H}$ : Their relations with each other and two alternative conceptualizations of reliability. Psychometrika, 70, 123-133. https://doi.org/10.1007/s11336-003-0974-7

\section{History}

Received February 20, 2019

Revision received February 14, 2020

Accepted February 14, 2020

Published online XX, 2020

EJPA Section / Category I/O Psychology

\section{Acknowledgment}

We are extremely grateful to Yanyun Yang for her help in computing all the indices in Study 1. [Author: ok?]

\section{Publication Ethics}

All three studies were conducted according to the ethical standards of the American Psychological Association (APA), and according to the principles expressed in the Declaration of Helsinki.
1138

1139

1140

1141

1142

1143

1144

1145

1146

1147

1148

1149

1150

1151

1152

1153

1154

1155

1156

1157

1158

1159

1160

1161

1162

1163

1164

1165

1166

1167

1168

1169

1170

1171

1172

1173

1174

1175

1176

1177

1178

1179

1180

1181

1182

1183

1184

1185

1186

1187

1188

1189

1190

1191

1192

1193

1194

1195

1196

1197

1198

1199 


\author{
Funding \\ This work has been supported by the Sapienza Università di Roma \\ (grant no. RM11715C809391B1) to Guido Alessandri, and by the \\ Provincia Autonoma di Trento (grant no. 40103205) to Enrico \\ Perinelli. [Author: ok?] \\ ORCID \\ (iD) Lorenzo Filosa \\ https://orcid.org/0000-0002-9748-1351
}

\section{Lorenzo Filosa}

Faculty of Medicine and Psychology

"Sapienza" University of Rome

Via dei Marsi, 78

00185 Rome

Italy

lorenzo.filosa@uniroma1.it

\section{Appendix}

\section{MAMS Items - English Version}

1. Because I can feel that it can allow me to do what I've always dreamed. (Intrinsic Regulation)

2. Because I really like working at the Guardia di Finan$z a$. (Intrinsic Regulation)

3. Honestly, I joined the Guardia di Finanza because I felt compelled. (Amotivation)

4. Because I can show that I can get ahead. (Introjected Regulation)

5. Because I want a well-paying job. (External Regulation)

6. To achieve the position I want in the future. (Identified Regulation)

7. I work at the Guardia di Finanza just because I have to. (Amotivation)

8. Because when I am worthy of the tasks I've been set, I feel important. (Identified Regulation)

9. Because it can allow me to reach the social status I've always wanted. (Identified Regulation)

10. I could not actually care less of being in Guardia di Finanza. (Amotivation)

11. To show that I am be very capable. (Introjected Regulation)

12. Because I want to earn more than people in other jobs. (External Regulation)

13. Because in Guardia di Finanza I can do things that I like. (Intrinsic Regulation)

14. Because it can provide me a carrier in which I can do what I've always wanted. (Intrinsic Regulation)

15. I sincerely do not know. I feel I'm wasting my time in Guardia di Finanza. (Amotivation)

16. To show that I'm able to do anything, if I want to. (Introjected Regulation)

17. Because I want to move up and make lots of money. (External Regulation)

\section{MAMS Items - Italian Version}

1. Perché sento che mi permetterà di fare quello che ho sempre sognato (Regolazione Intrinseca)

2. Perché mi piace veramente il lavoro in GdF (Regolazione Intrinseca)

3. Sinceramente sono entrato in GdF perché mi sono sentito costretto (Amotivazione)

4. Perché cosi posso far vedere che sono capace di fare carriera (Regolazione Introiettata)

5. Perché voglio avere un lavoro pagato molto bene (Regolazione Esterna)

6. Per poter arrivare in futuro alla posizione che desidero (Regolazione Identificata)

7. Lavoro in GdF solo perché devo farlo (Amotivazione)

8. Perché quando sono capace di essere all'altezza dei compiti che mi vengono assegnati mi sento importante (Regolazione Identificata)

9. Perché mi permette di arrivare alla posizione sociale che ho sempre desiderato (Regolazione Identificata)

10. A dire la verità non me ne importa nulla di essere in GdF (Amotivazione)

11. Per far vedere che sono in gamba (Regolazione Introiettata)

12. Perché voglio guadagnare di più di chi svolge altri lavori (Regolazione Esterna)

13. Perché in GdF posso fare cose che mi piacciono (Regolazione Intrinseca)

14. Perché mi offre una carriera che mi permetterà di fare ciò che ho sempre desiderato (Regolazione Intrinseca)

15. Sinceramente non lo so. Sento solo che sto perdendo tempo in GdF (Amotivazione)

16. Per far vedere che quando voglio posso riuscire in qualunque cosa (Regolazione Introiettata)

17. Perché voglio fare carriera e guadagnare tanti soldi (Regolazione Esterna) 